\title{
Human-induced changes to the global ocean water masses and their time of emergence
}

Article

Accepted Version

Silvy, Y., Guilyardi, E., Sallée, J.-B. and Durack, P. J. (2020) Human-induced changes to the global ocean water masses and their time of emergence. Nature Climate Change, 10. pp. 1030-1036. ISSN 1758-678X doi:

https://doi.org/10.1038/s41558-020-0878-x Available at https://centaur.reading.ac.uk/92392/

It is advisable to refer to the publisher's version if you intend to cite from the work. See Guidance on citing.

To link to this article DOI: http://dx.doi.org/10.1038/s41558-020-0878-x

Publisher: Nature

All outputs in CentAUR are protected by Intellectual Property Rights law, including copyright law. Copyright and IPR is retained by the creators or other copyright holders. Terms and conditions for use of this material are defined in the End User Agreement.

www.reading.ac.uk/centaur 
Central Archive at the University of Reading

Reading's research outputs online 
2 Human-induced changes to the global ocean water-masses

6 Yona Silvy ${ }^{1, *}$, Eric Guilyardi ${ }^{1,2}$, Jean-Baptiste Sallée $^{1}$ and Paul J. Durack ${ }^{3}$ 7

$8{ }^{1}$ LOCEAN-IPSL, Laboratoire d'Océanographie et du Climat : Expérimentation et

9 Approches Numériques (Sorbonne Université/CNRS/IRD/MNHN), Paris, France

$10 \quad{ }^{2}$ NCAS-Climate, University of Reading, UK

$11{ }^{3}$ Program for Climate Model Diagnosis and Intercomparison, Lawrence Livermore

12 National Laboratory, Livermore, California, USA

13

14

15 Corresponding author:

16 Yona Silvy (yona.silvy@locean-ipsl.upmc.fr)

17 LOCEAN-IPSL

18 Sorbonne Université, Boîte 100, 4 place Jussieu, 75252 Paris

19 


\section{0 [Abstract $]$}

21 The World Ocean is rapidly changing, with global and regional modification of 22 temperature and salinity, resulting in widespread and irreversible impacts. While

23 the most pronounced observed temperature and salinity changes are located in

24 the upper ocean, changes in water-masses at depth have been identified and will

25 likely strengthen in the future. Here, using 11 climate models, we define when 26 anthropogenic temperature and salinity changes are expected to emerge from 27 natural variability in the ocean interior along density surfaces. The models 28 predict that in 2020, 20-55\% of the Atlantic, Pacific and Indian basins have an 29 emergent anthropogenic signal; reaching $40-65 \%$ in 2050 , and $55-80 \%$ in 2080 .

30 The well-ventilated Southern Ocean water-masses emerge very rapidly, as early 31 as the 1980s-1990s, while the Northern Hemisphere emerges in the 2010s-2030s.

32 Our results highlight the importance of maintaining and augmenting an ocean 33 observing system capable of detecting and monitoring persistent anthropogenic 34 changes. 
[Main]

36 Observed ocean temperature and salinity changes have been partially attributed to

37 human activities, with global ocean heat content change identified in the early $2000 \mathrm{~s}^{1,2}$,

38 and temperature and salinity changes in the upper $(0-700 \mathrm{~m})$ and intermediate (700-

$392000 \mathrm{~m}$ ) ocean in more recent times ${ }^{3-11}$. A few studies focused on more specific

40 regions, with detected human-induced changes to ocean salinity in the Tropical

41 Pacific $^{9}$, the Atlantic ${ }^{10}$, and the Southern Ocean ${ }^{11}$. However, there are still vast regions

42 of the World Ocean, particularly at depth, where anthropogenic change remains

43 undetected. The lack of positive attribution can be due to poor observational coverage,

44 weak changes, or because natural variability is large and is hiding forced changes.

45 Because of the slow transport of heat and salt in the ocean interior, some regions in the

46 deep ocean may be isolated from human-induced changes for a long time as the climate

47 signal propagates from the surface to the ocean interior. Other regions, which are more

48 directly connected to the surface by atmosphere-ocean exchanges, ocean circulation

49 and mixing, may respond more quickly. Based on anthropogenically-forced climate

50 model simulations it is possible to estimate where and when the human-induced signal

51 emerges against the natural background climate variability in the ocean interior.

52

53 While investigating the timescale of anthropogenic signal emergence in the climate system, past studies have focused on surface temperature ${ }^{12-17}$, precipitation $^{18,19}$, sea level rise $\mathrm{e}^{20}$ as well as marine ecosystem drivers and ocean carbon cycle indicators ${ }^{21-}$

5626 . It was shown that temperature and salinity are potentially good indicators for 57 detecting anthropogenic change in the next few decades ${ }^{27}$. Here, we investigate for the 58 first time the emergence and associated probabilistic range of human-induced salinity changes at depth, in basin-scale zonal means, using a multi-model framework. We 
60 focus on the ocean interior below the "bowl", i.e. below the deepest winter mixed layer

61 and we use climate models participating in the 5th phase of the coupled model intercomparison project (CMIP5). Ocean circulation below the bowl primarily flows along density surfaces. Density surfaces can move vertically (heave) for several reasons including transient dynamical changes unrelated to atmosphere-forced and ocean-ingested heat or freshwater changes, that manifest as temperature and salinity changes when assessed on a given pressure level. In an endeavour to detect the earliest time of emergence, we therefore remove from our analysis all signal associated to transient dynamical change by investigating temperature and salinity changes on neutral density levels (see Methods). On a density surface, changes of salinity and temperature are by definition correlated, so to avoid redundancy we will hereafter only discuss salinity changes.

Observed zonally-averaged salinity changes along density surfaces show remarkably similar structures across different basins in the Southern Hemisphere (Figure 1a, Supplementary Figure 1a) ${ }^{28,29}$. These features include a subtropical freshening in the upper 1000 metres in the density range of Subantarctic Mode and Intermediate Waters $\left(26.5-27 \mathrm{~kg} \cdot \mathrm{m}^{-3}\right)$, surrounded by a relatively strong salinity increase in the tropical shallow cells and a slightly more moderate salinity increase in the range of Upper Circumpolar Deep Waters $\left(\sim 50^{\circ} \mathrm{S}-60^{\circ} \mathrm{S}, \sim 27.5 \mathrm{~kg} . \mathrm{m}^{-3}\right)$. The Northern Hemisphere Pacific presents a similar geographical salinification/freshening/salinification pattern

81 of change. The North Atlantic features a subpolar freshening extending into the 82 subtropics along the $27.7-28 \mathrm{~kg} \cdot \mathrm{m}^{-3}$ isopycnals as well as a freshening along the 27

$83 \mathrm{~kg} \cdot \mathrm{m}^{-3}$ isopycnal from the subtropics to the equator and southward, capped by a strong 84 salinity increase in the upper ocean and smaller increase at depth. Strong salinification 
is observed in the North Indian, spanning almost all density ranges and suggesting the influence of marginal sea outflows of high salinity dominates.

87 These large-scale patterns of multi-decadal change have been proposed to be caused by regional surface changes in freshwater fluxes ${ }^{29-32}$ (wet regions get wetter and dry regions get dryer), as well as from surface warming shifting isopycnal outcrops poleward and along which the signal penetrates the ocean interior ${ }^{30-32}$.

92 Although the amplitude of the change is weaker in the multi-model mean (MMM of 11 models; Figure $1 \mathrm{~b}$ and Supplementary Figure $1 \mathrm{~b}$ ) than in the observation-based estimate - which is expected for a multi-model ensemble mean as it washes out change patterns of water-masses with slightly different geographies thus not exactly aligned the main patterns of change are reproduced. Indeed, the observed salinification/freshening/salinification from equator to pole in the Southern Hemisphere of all three basins and in the Northern Hemisphere Pacific is replicated in the models, although we note the Mode Water freshening in the Southern Hemisphere

100 tends to appear on slightly lighter density classes in the models than in the observations

101 (around $26 \mathrm{~kg} \cdot \mathrm{m}^{-3}$ in the models versus $26.5-27 \mathrm{~kg} \cdot \mathrm{m}^{-3}$ in the observations), consistent with past studies ${ }^{11,31,33}$. The magnitude of change within the individual model ensembles is equivalent to observed estimates (Supplementary Figure 3) and the

104 change is robust across models in regions where the observed signal is the strongest, 105 indicative of a coherent forced change. The Northern Indian ocean shows a change 106 pattern of opposite sign in the MMM than in observations, as models have large 107 regional errors there. As the Durack \& Wijffels 2010 (hereafter DW10) analysis ends 108 in 2008 (Figure 1a), we also compute the 1950-2017 change using the EN4 ${ }^{34}$ 109 observation-based ocean reanalysis (Supplementary Figure 2a). The EN4 spatial 
110 patterns of change are extremely similar to those of DW10, giving confidence in the

111 robustness of these identified observed patterns. In the MMM, the patterns of change

112 identified during the 1950-2008 period (Figure $1 \mathrm{~b}$ and Supplementary Figure 1b)

113 become more robust when extending the period to 2017 and the amplitude of the

114 change increases (Supplementary Figure 2b).

115 To more quantitatively compare the observed and simulated trends in water-masses 116 regionally, a diagnostic of the trends in 9 regions of interest is shown (Figure 1c). In

117 both observations and models, these regions correspond to the salinity increase in the

118 subpolar Southern Ocean, the freshening in the Southern Hemisphere subtropics, the

119 increase (freshening) in the northern subtropical Atlantic (Pacific) and the increase in

120 the subpolar North Pacific. The coordinates are chosen to best capture these patterns

121 and tailored to the water-mass ranges of each model as those are not necessarily

122 reproduced at the same locations. Approximate boxes are shown in Figure 1a, and the

123 exact boxes can be found in Supplementary Figure 1a for the observations and

124 Supplementary Figure 4 for each model. We also run the same diagnostic for EN4.

125 Regional trends in the observational estimates and models (Figure 1c) are within the 126 same order of magnitude, although the DW10 values tend to lie systematically on the

127 higher end of the model distribution or even outside in some sections of the poorly-

128 sampled Southern Hemisphere, suggesting that the models might simulate a 129 conservative estimate of the change. In the well-sampled Northern Hemisphere, both 130 observational estimates fall within the model distribution. In all regions, EN4 yields a 131 smaller trend than DW10, consistent with the respective methods of these estimates 132 (in data-sparse regions, EN4 is restored towards the climatology, thus providing a very 133 conservative estimate of change). Overall, this gives us confidence in the ability of 134 models to reproduce these regional patterns of change. 
136 Based on the same model suite, we now determine the "anthropogenic" component of

137 the change by subtracting from the salinity computed in the historical simulations, the

138 salinity computed in idealized coincident simulations where human-induced forcings

139 are removed (historicalNat). At the end of the $20^{\text {th }}$ century it is striking that the

140 simulated historical change (Figure 1b) is very close to the estimated "anthropogenic"

141 contribution (Figure 2a), with a Pearson's spatial correlation coefficient of 0.88 ,

142 suggesting that human-induced forcings are responsible for most of the observed

143 salinity change during the $2^{\text {nd }}$ half of the $20^{\text {th }}$ century ${ }^{5,9-11}$. The pattern of the historical

144 anthropogenic signal is further amplified from 2006 and into the $21^{\text {st }}$ century under a

145 high emission scenario (RCP8.5; Figure 2b), confirming the robustness of the

146 structures of the anthropogenic forced change over the observed time period. As this

147 signal appears qualitatively robust and human-induced, we now investigate when it

148 can be statistically unambiguously distinguished from natural background variability

149 over the 1861-2100 period (note that unlike previous studies, we use "natural" rather

150 than "unforced" variability, see Methods).

152 We define the time of emergence (ToE) of salinity change as the year when the

153 anthropogenic signal (ranging from 1861 to 2100) exceeds and never falls back below

154 twice the typical natural variability "noise" threshold (the interannual standard

155 deviation of the historicalNat experiment), such that emergence is detected within the

$15695 \%$ confidence interval (see Methods for details). We are choosing a rather high

157 estimate of the noise envelope (see Methods), thus possibly yielding conservative ToE

158 results. Nevertheless, early detection is found: in all regions that show a robust pattern

159 of change, the multi-model median ToE falls between the late $20^{\text {th }}$ century and the first 
160 decades of the $21^{\text {st }}$ century (Figure $3 \mathrm{a}$ ) and there is a noteworthy agreement between

161 models on the sign of the signal (see also inter-model spread in Supplementary Figure

162 5). Regions that do not emerge show no agreement between models (grey areas in

163 Figure 3a). In 2020, most of the identified forced patterns have already emerged in the

164 ocean interior, with $20-45 \%$ of the zonally averaged basin emerged in the Atlantic; 20 -

$16555 \%$ in the Pacific and $25-50 \%$ in the Indian (Figure $3 b, 1^{\text {st }}-3^{\text {rd }}$ quartiles). These

166 numbers rapidly increase, reaching $35-55 \%$ in the Atlantic in 2050 to $55-65 \%$ in 2080;

$16745-65 \%$ to $60-75 \%$ in the Pacific; $45-65 \%$ to $60-80 \%$ in the Indian.

168

169 The earliest ToE are found in the Southern Hemisphere subtropical $\left(40-20^{\circ} \mathrm{S}\right)$ and

170 subpolar $\left(60-40^{\circ} \mathrm{S}\right)$ areas, with a median ToE as early as the $1980 \mathrm{~s}$, and overall earlier

171 than 2020. The subtropical Southern Ocean is a dominant region for heat uptake

172 associated with the formation and subduction of water-masses ventilating the

173 subtropical gyres with Mode and Intermediate waters ${ }^{33,35}$. The early emergence of the

174 human-induced signal in this region is consistent with the observed changes that have

175 been detected and attributed to anthropogenic forcings ${ }^{11}$. Model agreement in the

176 southern subtropical Atlantic from $40-20^{\circ} \mathrm{S}$ is weak in the upper $1000 \mathrm{~m}$, reflecting

177 that unlike the Indian and Pacific, this basin is not associated with a well ventilated

178 layer of Subantarctic Mode water ${ }^{35}$. Instead, the upper $1000 \mathrm{~m}$ in the Southern Ocean

179 Atlantic basin is populated with newly ventilated Intermediate waters ${ }^{35}$, whose

180 circulation and subduction are poorly represented by the CMIP5 model suite ${ }^{33}$. The

181 model spread is relatively narrow for the Southern Hemisphere subtropics (2-3 decades

182 for the interquartile range in the Pacific and Indian sectors; Supplementary Figure 5),

183 and slightly larger for the subpolar Southern Ocean. We note that the emergence in the

184 subpolar Southern Ocean is to be assessed cautiously, with most models rapidly 
185 limiting spurious open ocean deep convection due to near-surface freshening 36,37 , 186 therefore arguably warming at depth (1000-2000 m) much faster than in the real world

187 (in the subpolar Southern Ocean, deep convection acts to extract heat from the interior 188 ocean and release it to the atmosphere ${ }^{38}$ ). The other regions featuring an emergence of 189 the signal in the first decades of the $21^{\text {st }}$ century are the northern Pacific between 10 $19030^{\circ} \mathrm{N}$ and $40^{\circ} \mathrm{N}-60^{\circ} \mathrm{N}$, with a median ToE from the 2010 s to 2040 and an inter-model 191 range of a few decades. The signal in the North Atlantic also emerges in the early 192 decades of the $21^{\text {st }}$ century, mostly before 2020 , with an interquartile range of two to 193 four decades. The inter-model range gives a measure of the uncertainty that the climate

194 models are providing, and so a spectrum of possibilities for the real world to lie within.

195 There is decadal to multi-decadal variability between realizations and between models, 196 as well as model errors, which means it is difficult to get that range below $\mathrm{O}(10$ years).

198 Because each model can represent a given water-mass at slightly different latitude or 199 density, we again delineate model-specific water-mass ranges that are uniquely 200 defined for each model, so a clearer, quantitative water-mass centric model 201 intercomparison can be performed (same regions as Figure 1c; see approximate 202 regions in Figure $2 \mathrm{~b}$ and exact boxes for each model in Supplementary Figure 4 in 203 original density space). Additionally, and again to increase the signal to noise ratio, 204 because each model can have a different climate sensitivity for a given forcing 205 scenario, here we associate, for each model member, the ToE of the anthropogenic 206 signal in all 9 regions to the corresponding global mean surface warming at that time 207 under the RCP8.5 scenario (global mean surface air temperature (GSAT) increase 208 relative to the pre-industrial era, Figure 4). Supplementary Figure 6 shows the same 209 analysis, as a function of time (ToE axis instead of GSAT anomaly). 
210 Most models predict that salinity change signals emerge between $+0.5^{\circ} \mathrm{C}$ and $+2^{\circ} \mathrm{C}$ of

211 global mean surface warming, corresponding to a ToE between the late $20^{\text {th }}$ century

212 and the first decades of the $21^{\text {st }}$ century (Figure 4). According to this distribution, there

213 is a $100 \%$ probability for the anthropogenic signal in the Northern subpolar Pacific and

214 in the Southern Hemisphere Pacific and Indian subtropics to emerge before a $+2^{\circ} \mathrm{C}$

215 warming, and over $75 \%$ probability to emerge before $+1.5^{\circ} \mathrm{C}$ - and even before $+1^{\circ} \mathrm{C}$

216 for the Pacific southern subtropics (note observed global mean surface warming to

2172018 is about $\left.1^{\circ} \mathrm{C}^{39}\right)$. The subpolar Southern Ocean sectors have a relatively early

218 median emergence $\left(\sim 0.8^{\circ} \mathrm{C}-1.3^{\circ} \mathrm{C}\right)$, but a wide model spread, especially in the Pacific,

219 probably reflecting model deficiencies in representing this part of the ocean ${ }^{36,37}$. The

220 Northern Hemisphere subtropical water-masses emerge slightly later than their

221 Southern Hemisphere counterparts (except in the Atlantic basin), with about 75\%

222 probability to emerge before $+2.25^{\circ} \mathrm{C}$. We expect the dependence of these results to

223 slower warming scenarios (different RCPs) to be limited, as most models present a

224 signal emerging before there is a significant difference between scenarios (see

225 comparison of the RCP4.5 and RCP8.5 warming in Supplementary Figure 7).

226

227 We repeat the same analysis on an idealized emission scenario where CO2

228 concentration in the atmosphere increases by $1 \%$ every year (1pctCO2), i.e. a much

229 faster forcing than observed in the $20^{\text {th }}$ century or projected for the 21 st century (see

230 Supplementary Figures 6 and 8, and CO2 signal patterns in Supplementary Figure 9).

231 The overall agreement in the emergence of a climate signal in different water-masses

232 across the different models and the two types of very different timing of forcing

233 scenarios (RCP8.5, 1pctCO2) offers confidence in simulated emergence patterns and

234 confirms the dominant role of $\mathrm{CO} 2$ emissions. 
236 In analysing emergence timescales in the climate system, previous studies ${ }^{20,21}$ showed

237 that spatial patterns of ToE are strongly determined by the unforced variability, 238 meaning that an earlier ToE arises in regions of weaker noise and vice-versa. We 239 investigate whether this is the case by examining the relative contributions of signal 240 and noise to the ToE regional pattern for each model, as well as the regional inter241 model spread (see Supplementary Discussion and Supplementary Figures 12 and 13).

242 We find that the time-independent noise level is not sufficient to explain the ToE 243 spread, which seems predominantly explained by the signal across regions and models, 244 i.e. either its strength, or its decadal to multi-decadal variability. This suggests that the 245 low noise level of the ocean interior makes it a unique place for early detection of 246 human-induced changes, even with the conservative estimate used here. Indeed, 247 although the anthropogenic climate signal might appear at the surface first, strong 248 background variability there can delay its emergence and counter-intuitively earlier 249 emergence can be found in the ocean interior, with geographical differences compared 250 to the surface. Surface air temperature and sea surface temperature in the RCP8.5 251 scenario were found to emerge mainly within the early to mid $21^{\text {st }}$ century, showing 252 strong regional differences with earlier emergence in the tropics due to the low noise 253 level there than at higher latitudes ${ }^{14,15,20}$. ToE is especially late in the Southern Ocean 254 for surface temperature, whereas we find the earliest emergence in this part of the 255 world under the surface. Half of the ocean area is expected to have emergent 256 thermosteric sea level rise in the 2040s, and when including additional effects such as 257 ice mass loss, as early as $2020^{20}$. It is interesting to see that the timing of emergence 258 of changing patterns occurs differently for different variables, probably a testimony of 259 their distinctive interactions and feedbacks in the Earth system. This is clearly 
260 illustrated by the very different patterns and timing of emergence of the change in the

261 different components of the ocean carbon cycle ${ }^{26}$. The diversity of climate variables

262 investigated collectively provides a comprehensive understanding of the time of

263 emergence of the human-induced change in the Earth System, into which this study is

264 contributing additional insight.

266 This work suggests that a large portion of the observed change patterns in the ocean

267 interior is human-induced and will continue to respond to $\mathrm{CO} 2$ emissions. If these

268 patterns have been suggested to be primarily driven by an increased surface warming

269 and water-cycle amplification ${ }^{29,31}$ (two processes that directly affect heat and salt in

270 the ocean thus density and circulation), understanding how these patterns will continue

271 to amplify in the future in a more stratified upper ocean ${ }^{40}$ and with possibly modified

272 ocean circulation and mixing requires further investigation. In particular deciphering

273 which of the changing surface fluxes is likely to play a larger role, where and on what

274 timescales, can be for example explored with model-specific FAFMIP-like ${ }^{41,42}$

275 mechanistic studies.

276 The Hemispheric asymmetry in emergence, with earlier ToEs in the Southern

277 Hemisphere subtropics is reminiscent of a number of recent studies stressing the

278 importance of the Southern Ocean for ocean heat and carbon storage, associated with

279 the overturning circulation ${ }^{43-45}$. It is noteworthy that this part of the world is

280 historically the most poorly sampled, and therefore the worst positioned for detecting

281 a forced climate signal in observations ${ }^{46,47}$. The global pattern of human-induced

282 fingerprint of ocean interior change can be used to guide the future development of a

283 targeted global ocean observing system focused at monitoring and detecting future

284 ocean change. The maintenance of this observing system along with continued 
investment in climate and ocean model development and evaluation, will provide the necessary measurements and model tools to best inform adaptation and mitigation strategies and policies going forward.

\section{$290 \quad$ [Methods]}

\section{Density binning of CMIP5 simulations}

292 In this study, we use a suite of CMIP5 climate models binned into a neutral density 293 framework, using the McDougall and Jackett $(2005)^{48}$ routine, to examine 294 anthropogenic signal in the ocean on approximated neutral surfaces $\left(\gamma^{\mathrm{a}}\right)$ compared with 295 natural climate variability. Zonal means are computed for each oceanic basin along 296 neutral density surfaces, which allows for a more water mass-centric assessment than 297 is possible using a standard pressure level analysis. We note that some vertical 298 movement (heave) of density surfaces can be due to climate change ${ }^{49,50}$, but we don't 299 investigate those here. In addition to providing a cleaner signal and reducing the noise,

300 the density framework provides several other benefits, including a view of the ocean 301 interior delineated by its water-masses, useful for intermodel comparison ${ }^{33,51}$, as watermasses can be defined by their density range. Additionally, along density surfaces, salinity and temperature changes compensate and thus have the same structure and

304 sign, and consequently the same emergence timescale.

305 To allow for a simpler and more intuitive visual representation, zonally-averaged 306 values are then remapped back to a pseudo-depth coordinate using a $\gamma^{\mathrm{a}}$ to pressure 307 relationship derived from observation-based product $\mathrm{EN} 4^{34}$ by a surface-to-bottom 308 mapping of the ocean per density layer. Note that all remapping of this paper, 309 irrespective of whether we are in the context of past, contemporary, or future, is done 
310 with the exact same $\gamma^{\text {a }}$ to pressure relationship which is based on contemporary

311 observations. The remapping is purely a visual tool here, which does not introduce any

312 signal: all signal, noise and ToE computations are done in $\gamma^{\mathrm{a}}$ space. All the data is

313 trimmed at the bowl (i.e. below the winter mixed layer depth), indicated by a dark grey

314 shading in the figures.

315

\section{ToE definition}

317 The ToE is computed both locally (for each grid point; Figure 3 ) and regionally in a 318 number of determined regions, using a manual fingerprint (i.e. regional model-specific

319 boxes fixed in time) to track the signal (Figure 4). We use an ensemble of 11 models

320 with a total of 35 realizations for the anthropogenic ToE, and 13 single-member

321 models for the $\mathrm{CO}_{2}$ ToE (see Supplementary Table 1). The ToE is computed for each

322 individual member, then inter-member medians are derived, yielding a multi-model

323 distribution with the same weight for each model, and thus an estimate of the 324 uncertainty.

325 The anthropogenic signal is 240 years long, ranging from 1861 to 2100 . It is defined 326 over the historical period (1861-2005) at each yearly time step as the salinity difference

327 between the historical experiment (fully-forced) and the time averaged historicalNat

328 value (natural forcings only: solar fluctuations and volcanic eruptions); and defined 329 over the projection period (2006-2100) at each yearly time step by the salinity change 330 between the RCP8.5 scenario ("business as usual") and the time averaged historicalNat

331 value (same baseline for both periods to insure continuity). For each

332 historical+RCP8.5 ensemble member, the historicalNat time series used as the baseline 333 of the signal is the ensemble mean. 
334 We note that the correct term for the signal defined above should be "externally 335 forced" as the influence of external natural forcings can be present during the historical 336 period; however, considering the greater influence of human-induced forcings over

337 time and especially in the ocean interior, we therefore refer to this signal as 338 "anthropogenic". The possible influence of external natural forcings in the signal 339 during the historical period will occur in terms of additional decadal to multidecadal 340 variability.

341 The noise represents the bounds of background climate variability, and is built from

342 the interannual standard deviation of the historicalNat experiment (1861-2005, over 343145 years). Within several historical+RCP8.5 members of a model, the noise is the 344 same and is defined using the maximum standard deviation of all available 345 historicalNat realizations within that model. The threshold of signal exceedance over 346 noise is chosen at two based on the large consensus in existing literature, and because 347 it represents a $95 \%$ confidence of signal emergence, but sensitivity to this threshold is 348 discussed in the Supplementary Materials (see Supplementary Figure 10). Overall, this 349 definition makes it a rather high (thus conservative) estimate of the noise envelope 350 (interannual noise, historicalNat choice instead of a pre-industrial control, two 351 standard deviations as the threshold and picking the maximum among historicalNat 352 members). The signal is considered to have emerged if it definitively exceeds the noise 353 threshold at least 20 years before the end of the projection to account for potential 354 "false" emergence - i.e. if the signal were to go back within the bounds of climate 355 variability afterwards ${ }^{20,52}$. Note that some internal variability (and natural variability 356 over the historical period due to volcanic and sun forcings) remains in our signal 357 definition, which is not exactly the purely forced response to anthropogenic forcings 
such as can be identified with the multi-model mean of a large ensemble, but is rather a change and thus more similar to what real observational time series would look like.

360 The historicalNat experiment is a coherent choice for estimating natural climate

361 variability as it accounts for internal variability as well as external natural forcings,

362 both included in the forced experiments. However, we do test how our results are

363 affected by using the pre-industrial control (no external forcings) instead of the 364 historicalNat experiment in defining the noise, as is often done, and do not find the 365 time of emergence distributions to be much altered (see Supplementary Figure 11).

366 The change driven by the $\mathrm{CO} 2$ forcing alone can be estimated in a similar way, by

367 taking the salinity difference between the yearly idealized 1pctCO2 experiment (140

368 years) and the mean value of the pre-industrial control. The noise for $\mathrm{CO} 2 \mathrm{ToE}$ is then

369 defined as the standard deviation of the pre-industrial control over the last 240 years

370 (as to have the same noise definition as done in Supplementary Figure 11 for the 371 turquoise boxes).

\section{ToE distribution of basin zonal means}

374 The gridpoint-per-gridpoint ToE distribution is calculated based on Lyu et al.'s $375(2014)^{20}$ methodology. A signal is considered to have emerged if its ToE is at least 20 376 years earlier than the end of the time series (2080 for the RCP8.5, 120 for the 377 1pctCO2). At each gridpoint, the signal of each model realization can emerge with 378 either a positive (salinity increase) or negative (freshening) change, or not emerge at 379 all and stay within the bounds of climate variability. The distribution can be calculated 380 if at least half of the runs emerge with the same sign of the signal, or at least half of 381 the runs show no emergence, and if the outliers that have a different direction of change 382 are less than 5 ( 5 for the anthropogenic signal, 1 for the pure CO2). We then compute 
383 the distribution by excluding the outliers, first by computing the inter-member 384 medians, then the multi-model distribution using these medians so as to give each

385 model the same weight. If the conditions are not met, the location is labelled as "no 386 agreement”. See Lyu et al. (2014) supplementary material for details and examples.

\section{Manual fingerprint}

389 The regional ToEs are calculated by averaging both signal and noise in selected regions

390 (see Figure 2b). Namely, we defined: the Southern Ocean subpolar range, 391 encompassing signal associated with Upper Circumpolar Deep Water (around 40$\left.39260^{\circ} \mathrm{S} ; 27-28 \mathrm{~kg} . \mathrm{m}-3\right)$; the Southern Ocean subtropical range, encompassing signal 393 associated with Mode and Intermediate Waters (around 20-40 $\mathrm{S} ; 25-26.5 \mathrm{~kg} . \mathrm{m}-3$ ); the

394 Northern Hemisphere subtropical range, encompassing signal associated with Atlantic 395 and Pacific Mode Waters (around 20-40N; 25-26 kg.m-3 in the Pacific; 26-27 kg.m-

3963 in the Atlantic), and the Subpolar North Pacific, encompassing signal associated with 397 the North Pacific Intermediate Waters (around 40-60º ; 26-27 kg.m-3). The boxed 398 coordinates are model-specific, and were fixed (in $\gamma^{\mathrm{a}}$ space) based on the zonallyaveraged spatial pattern of the signal at the end of the time series (see Supplementary

400 Figure 4). The regional emergence of the signal (Figure 4) is based on a manual 401 fingerprint for each region displayed, thus slightly sensitive to the precise boxes used.

402 The patterns of change that already exist in the historical forced simulations continue 403 to exist in the same locations and enhance in the $21^{\text {st }}$ century simulations, giving us 404 confidence in using boxes fixed in time. 
409 Global surface warming at emergence was computed by taking each run's GSAT 410 (historical+RCP8.5) smoothed with a 10-year running mean, at the time of emergence

411 in each region. GSAT anomaly is calculated relative to the $1850-1900$ period. The 412 same was done for the 1pctCO2 GSAT (Supplementary Figure 8).

413

\section{Percentage of basin emergence}

415 We define the percentage of emerged area in basin zonal means and under the surface

416 bowl at each time step by computing the cumulative sum over each basin of the number

417 of grid cells that have emerged before that time step, weighted by the thickness of their 418 respective density layer; and dividing it by the cumulative sum of each grid cell's

419 isopycnal thickness of that same basin zonal mean. The result is given in terms of area 420 as the latitudinal grid is regular with a $1^{\circ}$ resolution (all models were interpolated on

421 that same horizontal regular grid). This is done for every model simulation, then the 422 inter-member medians are computed. Shown in Figure $3 \mathrm{~b}$ are the median, $1^{\text {st }}$ and $3^{\text {rd }}$ 423 quartiles of the multi-model distribution. 


\section{3 [Acknowledgments]}

434 We wish to thank Casimir de Lavergne, Alexey Fedorov, Peter Gleckler, Jonathan 435 Gregory, Ed Hawkins, Gurvan Madec, Herlé Mercier, Juliette Mignot, Ben Santer and 436 Laurent Terray for helpful discussions. We acknowledge the support from the "Make Our 437 Planet Great Again” project ARCHANGE (Agence Nationale pour la Recherche project 438 ANR-18-MPGA-0001), from the European Research Council (ERC) under the European 439 Union's Horizon 2020 research and innovation program (grant agreement 637770) and 440 from the Centre National de la Recherche Scientifique. We also acknowledge the CMIP5 441 modelling groups, the ESGF and IPSL/ESPRI-MOD data distribution systems. The work 442 of PJD was prepared by Lawrence Livermore National Laboratory (LLNL) under 443 Contract DE-AC52-07NA27344 and is a contribution to the U.S. Department of Energy, 444 Office of Science, Climate and Environmental Sciences Division, Regional and Global 445 Modeling and Analysis Program. LLNL Release number: LLNL-JRNL-794900. 


\section{[References]}

459 1. Barnett, T. P., Pierce, D. W. \& Schnur, R. Detection of Anthropogenic Climate 460 Change in the World's Oceans. Science 292, 270-274 (2001).

4612 2. Reichert, B. K., Schnur, R. \& Bengtsson, L. Global ocean warming tied to 462 anthropogenic forcing. Geophys. Res. Lett. 29, 20-1-20-4 (2002).

463 3. Barnett, T. P. et al. Penetration of Human-Induced Warming into the World's 464 Oceans. Science 309, 284-287 (2005).

465 4. Palmer, M. D., Good, S. A., Haines, K., Rayner, N. A. \& Stott, P. A. A new 466 perspective on warming of the global oceans. Geophys. Res. Lett. 36, (2009).

467 5. Pierce, D. W., Gleckler, P. J., Barnett, T. P., Santer, B. D. \& Durack, P. J. The

468 fingerprint of human-induced changes in the ocean's salinity and temperature fields.

469 Geophys. Res. Lett. 39, (2012).

470 6. Gleckler, P. J. et al. Human-induced global ocean warming on multidecadal

471 timescales. Nat. Clim. Change 2, 524-529 (2012).

472 7. Tokarska, K. B., Hegerl, G. C., Schurer, A. P., Ribes, A. \& Fasullo, J. T.

473 Quantifying human contributions to past and future ocean warming and thermosteric sea 474 level rise. Environ. Res. Lett. 14, 074020 (2019).

475 8. Bilbao, R. A. F., Gregory, J. M., Bouttes, N., Palmer, M. D. \& Stott, P.

476 Attribution of ocean temperature change to anthropogenic and natural forcings using the 477 temporal, vertical and geographical structure. Clim. Dyn. (2019) doi:10.1007/s00382478 019-04910-1.

479 9. Terray, L. et al. Near-Surface Salinity as Nature's Rain Gauge to Detect Human 480 Influence on the Tropical Water Cycle. J. Clim. 25, 958-977 (2012).

481 10. Stott, P. A., Sutton, R. T. \& Smith, D. M. Detection and attribution of Atlantic 482 salinity changes. Geophys. Res. Lett. 35, (2008).

483 11. Swart, N. C., Gille, S. T., Fyfe, J. C. \& Gillett, N. P. Recent Southern Ocean 484 warming and freshening driven by greenhouse gas emissions and ozone depletion. Nat. 485 Geosci. 11, 836-+ (2018).

486 12. Mahlstein, I., Knutti, R., Solomon, S. \& Portmann, R. W. Early onset of 487 significant local warming in low latitude countries. Environ. Res. Lett. 6, 034009 488 (2011).

489 13. Diffenbaugh, N. S. \& Scherer, M. Observational and model evidence of global 490 emergence of permanent, unprecedented heat in the 20th and 21st centuries. Clim. 
492 14. Hawkins, E. \& Sutton, R. Time of emergence of climate signals. Geophys. Res.

493 Lett. 39, n/a-n/a (2012).

494 15. Mora, C. et al. The projected timing of climate departure from recent variability.

495 Nature 502, 183-187 (2013).

496 16. Diffenbaugh, N. S. \& Charland, A. Probability of emergence of novel

497 temperature regimes at different levels of cumulative carbon emissions. Front. Ecol.

498 Environ. 14, 418-423 (2016).

499 17. Lehner, F., Deser, C. \& Terray, L. Toward a New Estimate of "Time of

500 Emergence" of Anthropogenic Warming: Insights from Dynamical Adjustment and a

501 Large Initial-Condition Model Ensemble. J. Clim. 30, 7739-7756 (2017).

502 18. Giorgi, F. \& Bi, X. Time of emergence (TOE) of GHG-forced precipitation

503 change hot-spots. Geophys. Res. Lett. 36, (2009).

504 19. Mahlstein, I., Portmann, R. W., Daniel, J. S., Solomon, S. \& Knutti, R.

505 Perceptible changes in regional precipitation in a future climate. Geophys. Res. Lett. 39, 506 (2012).

507 20. Lyu, K., Zhang, X., Church, J. A., Slangen, A. B. A. \& Hu, J. Time of

508 emergence for regional sea-level change. Nat. Clim. Change 4, (2014).

509 21. Keller, K. M., Joos, F. \& Raible, C. C. Time of emergence of trends in ocean

510 biogeochemistry. Biogeosciences 11, 3647-3659 (2014).

511 22. Rodgers, K. B., Lin, J. \& Frölicher, T. L. Emergence of multiple ocean

512 ecosystem drivers in a large ensemble suite with an Earth system model. Biogeosciences

513 12, 3301-3320(2015).

514 23. Frölicher, T. L., Rodgers, K. B., Stock, C. A. \& Cheung, W. W. L. Sources of

515 uncertainties in 21 st century projections of potential ocean ecosystem stressors. Glob.

516 Biogeochem. Cycles 30, 1224-1243 (2016).

517 24. Henson, S. A. et al. Rapid emergence of climate change in environmental

518 drivers of marine ecosystems. Nat. Commun. 8, 14682 (2017).

519 25. Turk, D. et al. Time of Emergence of Surface Ocean Carbon Dioxide Trends in

520 the North American Coastal Margins in Support of Ocean Acidification Observing

521 System Design. Front. Mar. Sci. 6, (2019).

522 26. Schlunegger, S. et al. Emergence of anthropogenic signals in the ocean carbon

523 cycle. Nat. Clim. Change 1-7 (2019) doi:10.1038/s41558-019-0553-2.

524 27. Banks, H. \& Wood, R. Where to Look for Anthropogenic Climate Change in the 
526 28. Helm, K. P., Bindoff, N. L. \& Church, J. A. Changes in the global hydrological527 cycle inferred from ocean salinity. Geophys. Res. Lett. 37, (2010).

528 29. Durack, P. J. \& Wijffels, S. E. Fifty-Year Trends in Global Ocean Salinities and 529 Their Relationship to Broad-Scale Warming. J. Clim. 23, 4342-4362 (2010).

$530 \quad 30 . \quad$ Durack, P. J., Wijffels, S. E. \& Matear, R. J. Ocean Salinities Reveal Strong

531 Global Water Cycle Intensification During 1950 to 2000. Science 336, 455-458 (2012).

532 31. Lago, V. et al. Simulating the Role of Surface Forcing on Observed

533 Multidecadal Upper-Ocean Salinity Changes. J. Clim. 29, 5575-5588 (2016).

534 32. Zika, J. D. et al. Improved estimates of water cycle change from ocean salinity:

535 the key role of ocean warming. Environ. Res. Lett. 13, 074036 (2018).

536 33. Sallee, J.-B. et al. Assessment of Southern Ocean water mass circulation and

537 characteristics in CMIP5 models: Historical bias and forcing response. J. Geophys.

538 Res.-Oceans 118, 1830-1844 (2013).

539 34. Good, S. A., Martin, M. J. \& Rayner, N. A. EN4: Quality controlled ocean

540 temperature and salinity profiles and monthly objective analyses with uncertainty 541 estimates: THE EN4 DATA SET. J. Geophys. Res. Oceans 118, 6704-6716 (2013).

$542 \quad 35 . \quad$ Sallée, J.-B., Speer, K., Rintoul, S. \& Wijffels, S. Southern Ocean Thermocline 543 Ventilation. J. Phys. Oceanogr. 40, 509-529 (2010).

544 36. de Lavergne, C., Palter, J. B., Galbraith, E. D., Bernardello, R. \& Marinov, I.

545 Cessation of deep convection in the open Southern Ocean under anthropogenic climate 546 change. Nat. Clim. Change 4, 278-282 (2014).

547 37. Heuzé, C., Ridley, J. K., Calvert, D., Stevens, D. P. \& Heywood, K. J.

548 Increasing vertical mixing to reduce Southern Ocean deep convection in NEMO3.4.

549 Geosci. Model Dev. 8, 3119-3130 (2015).

550 38. Dufour, C. O. et al. Preconditioning of the Weddell Sea Polynya by the Ocean

551 Mesoscale and Dense Water Overflows. J. Clim. 30, 7719-7737 (2017).

552 39. Intergovernmental Panel on Climate Change. Summary for Policymakers. in

553 Global warming of $1.5^{\circ} \mathrm{C}$. An IPCC Special Report on the impacts of global warming of

$554 \quad 1.5^{\circ} \mathrm{C}$ above pre-industrial levels and related global greenhouse gas emission

555 pathways, in the context of strengthening the global response to the threat of climate

556 change, sustainable development, and efforts to eradicate poverty (2018).

557 40. Yamaguchi, R. \& Suga, T. Trend and Variability in Global Upper-Ocean

558 Stratification Since the 1960s. J. Geophys. Res. Oceans 124, 8933-8948 (2019). 
559 41. Gregory, J. M. et al. The Flux-Anomaly-Forced Model Intercomparison Project 560 (FAFMIP) contribution to CMIP6: investigation of sea-level and ocean climate change 561 in response to $\mathrm{CO} 2$ forcing. 27 (2016).

562 42. Todd, A. et al. Ocean-only FAFMIP: Understanding Regional Patterns of Ocean 563 Heat Content and Dynamic Sea Level Change. (2020).

564 43. Gille, S. T. Decadal-Scale Temperature Trends in the Southern Hemisphere 565 Ocean. J. Clim. 21, 4749-4765 (2008).

566 44. Khatiwala, S. P. et al. Global ocean storage of anthropogenic carbon.

567 Biogeosciences 10, 2169-2191 (2013).

568 45. Frölicher, T. L. et al. Dominance of the Southern Ocean in Anthropogenic

569 Carbon and Heat Uptake in CMIP5 Models. J. Clim. 28, 862-886 (2015).

570 46. Roemmich, D. et al. Unabated planetary warming and its ocean structure since 571 2006. Nat. Clim. Change 5, 240-245 (2015).

572 47. Durack, P. J., Gleckler, P. J., Landerer, F. W. \& Taylor, K. E. Quantifying

573 underestimates of long-term upper-ocean warming. Nat. Clim. Change 4, 999-1005 574 (2014).

575 48. McDougall, T. J. \& Jackett, D. R. The material derivative of neutral density. J. 576 Mar. Res. 63, 159-185 (2005).

577 49. Häkkinen, S., Rhines, P. B. \& Worthen, D. L. Warming of the Global Ocean:

578 Spatial Structure and Water-Mass Trends. J. Clim. 29, 4949-4963 (2016).

579 50. Desbruyères, D., McDonagh, E. L., King, B. A. \& Thierry, V. Global and Full580 Depth Ocean Temperature Trends during the Early Twenty-First Century from Argo 581 and Repeat Hydrography. J. Clim. 30, 1985-1997 (2017).

582 51. Iudicone, D. et al. Water masses as a unifying framework for understanding the 583 Southern Ocean Carbon Cycle. Biogeosciences 8, 1031-1052 (2011).

584 52. Hawkins, E. et al. Uncertainties in the timing of unprecedented climates. Nature 585 511, E3-E5 (2014). 

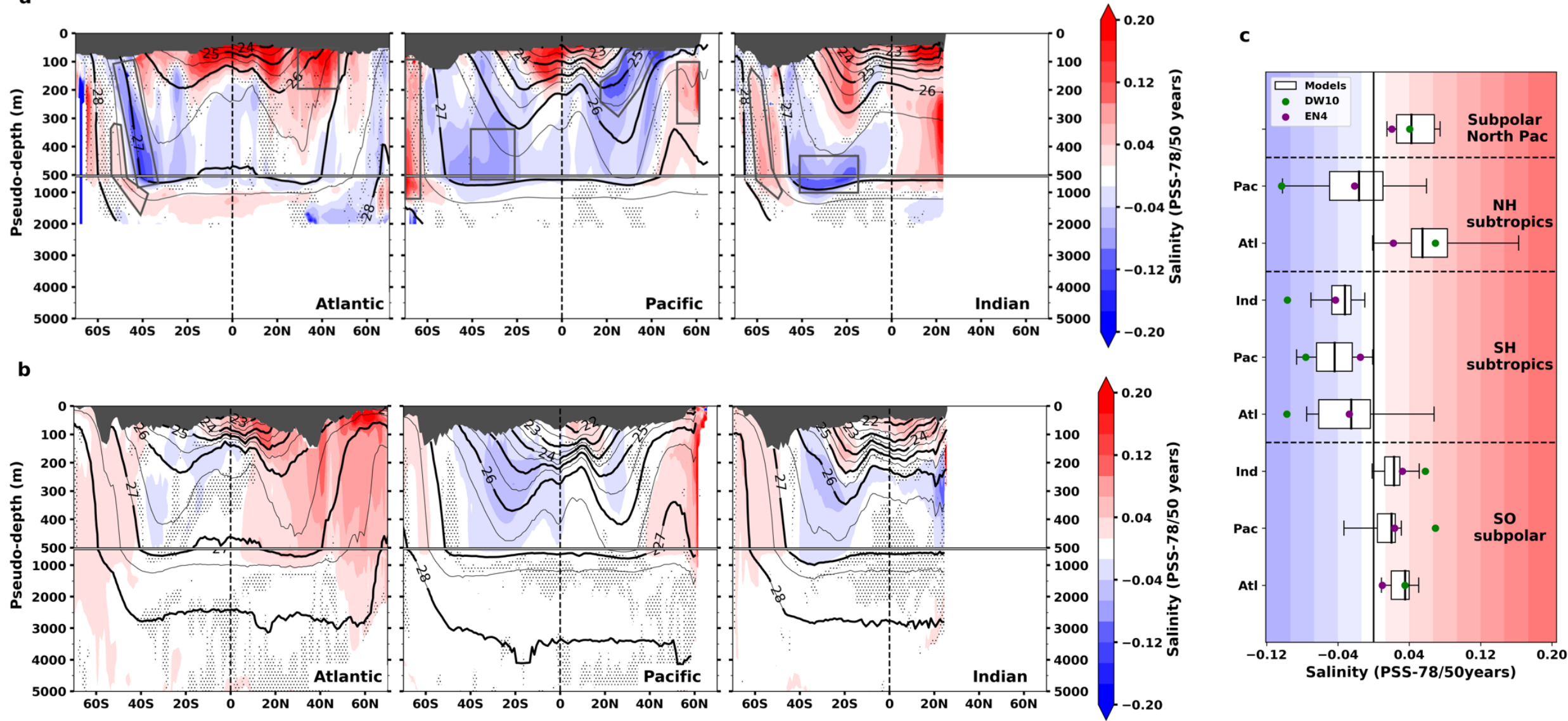

Figure 1 Observed and simulated salinity changes between 1950 and 2008, shown in PSS-78/50 years, analysed on density surfaces. For ease of reading all figures of this paper are projected back from density to pressure as vertical coordinate (see Methods). (a) From Durack \& Wijffels (2010) observation-based analysis. Contours show isopycnals and stipples where the trend is not significant at the 90\% confidence level. (b) From the multi-model mean historical experiments. Contours show isopycnals and stipples indicate where less than $60 \%$ of models agree on the sign of the trend. The changes in original density coordinate are shown in Supplementary Figure 1. (c) Trend averaged in 9 regions (approximate boxes shown in panel a) for 2 observational estimates (Durack \& Wijffels 2010 - DW10 - and EN4) and for the model distribution (boxes indicate $1^{\text {st }}$ and $3^{\text {rd }}$ quartiles and the median; whiskers indicate the minimum and maximum outliers). The shading in (c) corresponds to the colour scale of (a) and (b). The exact regions in density space as used for each observational dataset and model are plotted in Supplementary Figures 1a, 2a and 4 (same coordinates for both observational datasets). The greyed-out regions 97 at the surface correspond to data trimming above the bowl - see text. 
a
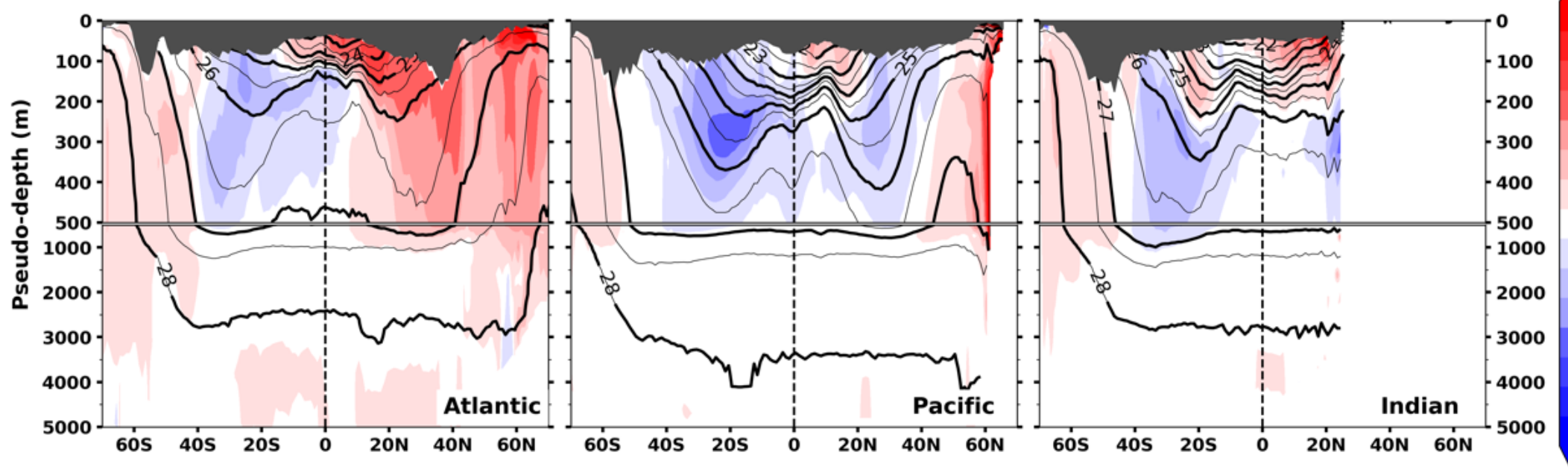

0.20

$-0.12$

0.04

ผุ่

$-0.04 \stackrel{?}{5}$

$-0.12$

$-0.20$

b
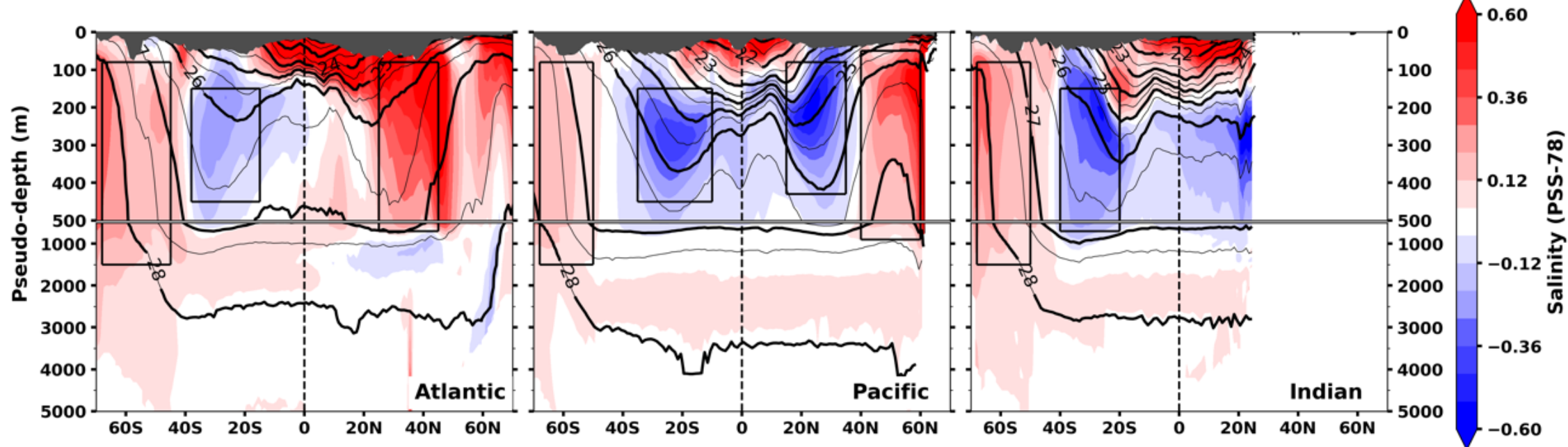

Figure 2 Anthropogenic salinity change along density surfaces. (a) At the end of the 20th century (multi-model mean difference between the last 20 years - to account for potential decadal variability - of the historical experiment and the historicalNat experiment). (b) At the end of the $21^{\text {st }}$ century (multi-model mean difference between the last 20 years of the RCP8.5 scenario and the average of the whole historicalNat experiment). Boxes in (b) represent the approximate regions in which salinity trends are computed in Figure $1 \mathrm{c}$ and in which time of emergence is calculated in Figure 4. The same signal as in (b)

is shown in Supplementary Figure 4 for each model in density space with the exact box locations. 
a

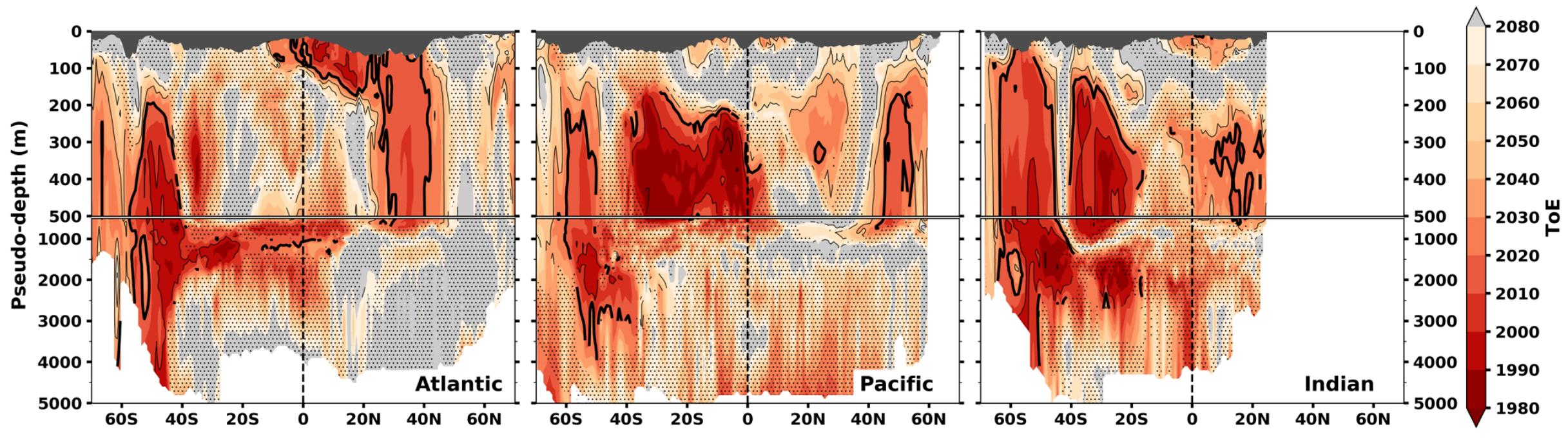

b
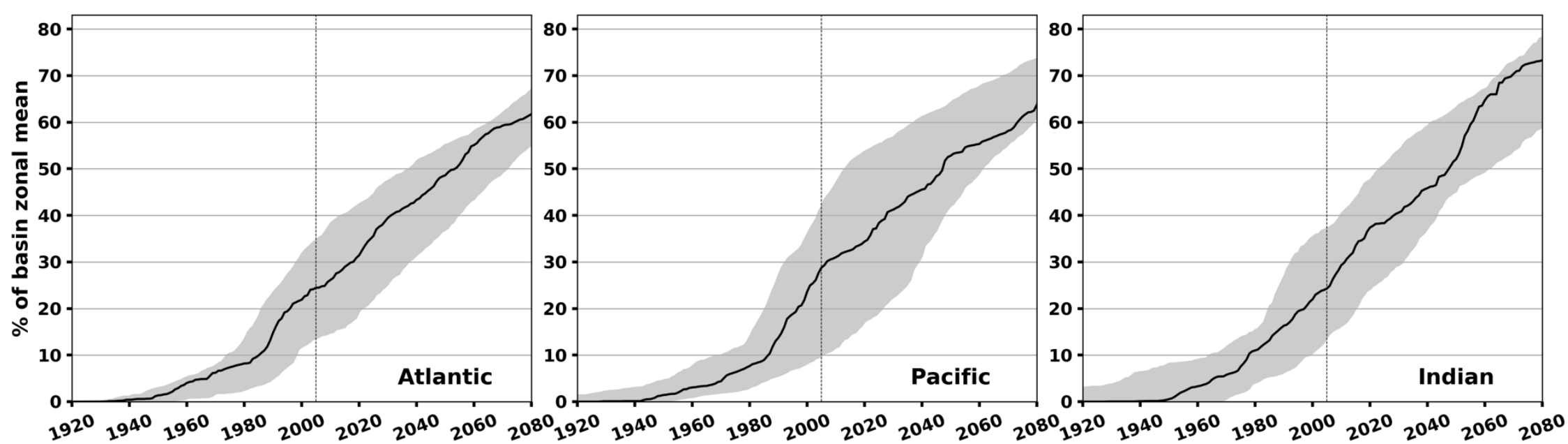

Figure 3 Time of emergence and percentage of emergence in basin zonal-means. (a) Multi-model median time of emergence of the anthropogenic salinity change, calculated for an ensemble of 11 models. Light grey regions mean no emergence of the signal, while stippled regions show where the models don't agree on the sign of the signal (see Methods). Bold contour is year 2020. (b) Percentage of basin emergence in zonal means under the bowl (see Methods).

The black line is the median, the grey shading is the interquartile range. 


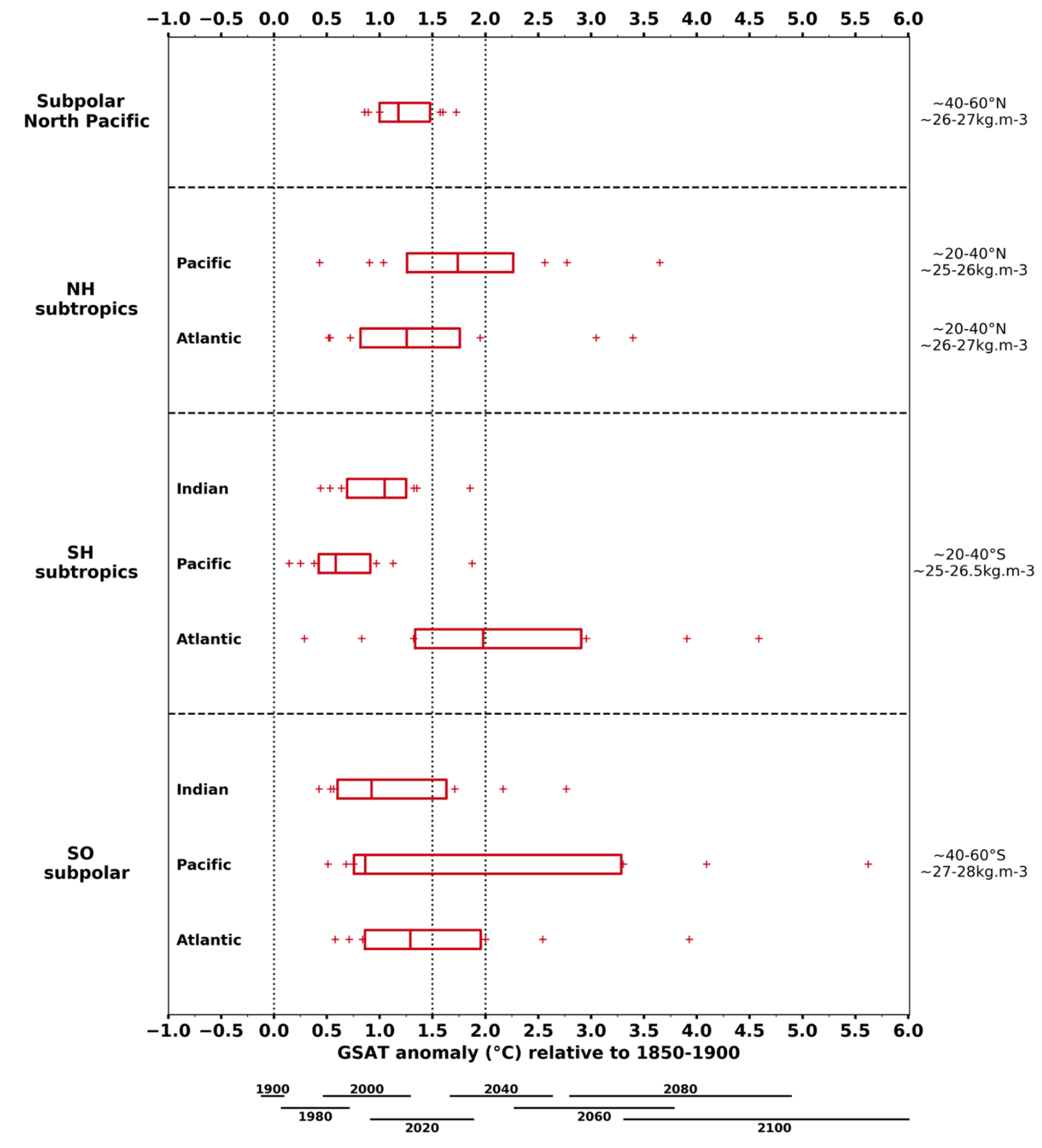
models in 9 regions of interest: the Southern Ocean subpolar range, the Southern Hemisphere subtropical range, the Northern Hemisphere subtropical range and the subpolar North Pacific (the exact coordinates for each model are shown in Supplementary Figure 4). Red boxes indicate $1^{\text {st }}$ quartile, median and $3^{\text {rd }}$ quartile. historical and RCP8.5 simulations. 